\title{
When it comes to stewardship, it's time to get with the programmers
}

\author{
Elizabeth CT Parfitt MD FRCPC ${ }^{1}$, Louis Valiquette MD MSc FRCPC ${ }^{2}$, Kevin B Laupland MD MSc FRCPC 1,3
}

$\mathrm{R}$ educing antimicrobial use is believed to be a critical intervention in an era of impending catastrophic drug resistance, with little promise in the antimicrobial pipeline $(1,2)$. Up to one-half of human antimicrobial use is believed to be inappropriate in terms of indication, choice of agent or duration (3). After years of research, it is clear that the most important determinant of resistance development is the use of an antimicrobial $(4,5)$. In an effort to counteract overuse, Accreditation Canada now mandates, in its Required Organizational Practices, the existence of a multidisciplinary antimicrobial stewardship program (ASP) at most inpatient health care facilities, including long-term care facilities providing 'complex continuing care' (6). Successful ASPs have demonstrated benefits including reduced drug resistance, fewer Clostridium difficile infections and reduced antimicrobial-related toxicity, with no demonstrated adverse clinical outcomes $(7,8)$.

Infectious diseases (ID) physicians and microbiologists are natural champions of ASPs with our fund of knowledge and ability to assess 'appropriateness' of antimicrobial use. However, most antimicrobial decisions never involve an ID physician. The challenges ASPs face are reaching individual prescribers, the vast majority of whom are primary care providers (9), and changing what are well-entrenched behavioural patterns (10).

An ASP is tasked with knowledge translation, defined by the Canadian Institutes of Health Research as "a dynamic and iterative process that includes synthesis, dissemination, exchange and ethicallysound application of knowledge" (11). Locally tailored clinical practice guidelines are created based on drug-resistance patterns and formulary to simplify and standardize antimicrobial decision making a critical activity for any ASP. This vital information is often closeted on the health region's intranet or delivered in colleagues' mailboxes as laminated pocketcards. There may be little in the way of uptake (12) due to many barriers, which include lack of awareness of the available information, poor usability of a guideline (overly technical, too vague or too much information), lack of individualization or, perhaps, attitudinal factors of the prescriber, such as perceived loss of autonomy or skepticism (13). To be successful in overcoming these barriers, we need to engage a variety of skill sets beyond our own, particularly social marketing, human factors and, perhaps most importantly, health information technology (IT) experts.

Given the vast amount of dynamic information directed from clinical, microbiological and evidenced-based literature sources, leveraging health IT in the antimicrobial stewardship efforts appears to be an obvious way forward. The use of IT is significantly associated with improvements in clinical practice when considering clinical decision support (14). Well-designed software can be viewed as the medium in which ASP activities and interactions are conducted. Multidisciplinary ASP members, including physician and pharmacist content experts, end-users, social marketers and human factors experts contribute to software design and functionality.
IT platforms can execute or facilitate virtually all stewardship activities catalogued by the Infectious Disease Society of America Antimicrobial Stewardship guidelines (7). For example, audit and feedback is greatly enhanced by the use of software, with improved case finding and uptake of recommendations because they are delivered in a timely and actionable manner (15), and the technology facilitates communication between the provider and ASP (16).Automatic messages for highly bioavailable oral agents prescribed by the intravenous route can be generated to remind providers to convert to the enteral route unless there is good reason. The tedious process of obtaining data needed for optimal prescribing, such as recent antimicrobials, microbiology reports, organ function, drug allergies and interactions, can be easily displayed to the user, improving clinical efficiency. The conversion of local clinical practice guidelines into rule-based algorithms can rapidly provide individualized patient management recommendations. The same platform can be used to evaluate the ASP activities by collecting data on antimicrobial use and cost, drug resistance, number of recommendations (versus accepted) and patient outcomes.

Ideally, any IT program for ASP implementation is seamlessly integrated, reducing the need for manual entry by obtaining necessary data from the electronic health record (EHR), and computerized order entry ASP recommendations are immediately actionable. Pairing recommendations with the order entry system provides a so-called 'forcing function', a strong mediator of behavioural change (17) according to the human factors literature. In the United States (US), with multiple billions invested in incentivized 'meaningful use' EHR adoptions (18), there has been a sharp acceleration in the rate of EHR uptake (19). Epic (Wisconsin, USA) and Cerner (Missouri, USA), the EHRs with the largest US market share, particularly for larger organizations, are reported to be increasing their ASP capabilities within the software (16). Third-party vendors have produced 'add-on' software to address gaps in the EHR ASP functionality, the most developed of which is probably TheraDoc, evolved from the long established and fruitful ASP at LDS Hospital in Utah (USA) (a branch of Intermountain Health) (16). Such software is typically more elegant and robust for ASP activities compared with the EHR itself, but can represent additional significant cost on top of the core EHR (20).

Integrated IT systems for use by the ASP exist in Canada in centres with more established stewardship programs. The Antimicrobial Prescription Surveillance System (APSS) has been developed and validated at the Université de Sherbrooke (Sherbrooke, Quebec), and is fully implemented at the Centre Hospitalier Universitaire de Sherbrooke (CHUS) (Sherbrooke, Quebec) since August 2010. Its broad knowledge base identifies mismatches between guidelines and prescriptions to flag patients who would benefit from pharmacist intervention. At the CHUS, after 20 months of use, it has been associated with a $\$ 705,000$ reduction in antimicrobial costs and $13 \%$ in overall antimicrobial consumption (21). Prescriber acceptance of recommendations, at $>90 \%$, has not been limited by paper-based order entry.

${ }^{1}$ Department of Medicine, Royal Inland Hospital, Kamloops, British Columbia; ${ }^{2}$ Department of Microbiology-Infectious Diseases, Université de Sherbrooke, Sherbrooke, Quebec; ${ }^{3}$ Departments of Medicine, Critical Care Medicine, Pathology and Laboratory Medicine, and Community Health Sciences, University of Calgary, Calgary, Alberta

Correspondence: Dr Kevin B Laupland, Royal Inland Hospital, 311 Columbia Street, Kamloops, British Columbia V2C 2T1.

Telephone 250-374-5111, e-mail klaupland@gmail.com 
TABLE 1

Antimicrobial stewardship focused smartphone apps

\begin{tabular}{|c|c|c|c|c|c|c|c|c|}
\hline \multirow[b]{2}{*}{ App title } & \multirow[b]{2}{*}{ Content developer } & \multicolumn{6}{|c|}{ Features } & \multirow[b]{2}{*}{$\begin{array}{l}\text { Algorithmic } \\
\text { format }\end{array}$} \\
\hline & & Antibiograms & $\begin{array}{c}\text { Local } \\
\text { guidelines }\end{array}$ & $\begin{array}{c}\text { Epidemiology } \\
\text { trends }\end{array}$ & $\begin{array}{l}\text { Pathogen } \\
\text { information }\end{array}$ & $\begin{array}{c}\text { Drug prescribing } \\
\text { information }\end{array}$ & $\begin{array}{c}\text { Stewardship } \\
\text { recommendations }\end{array}$ & \\
\hline Bugs and Drugs & $\begin{array}{l}\text { Alberta Health } \\
\text { Services, Alberta, }\end{array}$ & & & & $x$ & $x$ & $x$ & \\
\hline GAPP guidelines & $\begin{array}{l}\text { Galway University } \\
\text { Hospitals, Galway, } \\
\text { Ireland }\end{array}$ & & $x$ & & & $x$ & $x$ & \\
\hline Infections & $\begin{array}{l}\text { National Health } \\
\text { Service, London, } \\
\text { United Kingdom }\end{array}$ & & $x$ & & & & $x$ & \\
\hline $\begin{array}{l}\text { Intermountain Physician } \\
\text { GermWatch }\end{array}$ & $\begin{array}{l}\text { Intermountain } \\
\text { Healthcare, } \\
\text { Salt Lake City, USA }\end{array}$ & $x$ & & $x$ & & & & \\
\hline $\begin{array}{l}\text { RCSI Hospitals Group } \\
\text { Antimicrobial Guidelines }\end{array}$ & $\begin{array}{l}\text { Royal College of } \\
\text { Surgeons in Ireland, } \\
\text { Dublin, Ireland }\end{array}$ & & $x$ & & & $x$ & $x$ & \\
\hline Rx Guidelines & $\begin{array}{l}\text { National Health } \\
\text { Service, United } \\
\text { Kingdom }\end{array}$ & & $x$ & & & $x$ & $x$ & \\
\hline $\begin{array}{l}\text { Sligo Regional Hospital } \\
\text { Antimicrobial Prescribing } \\
\text { Guide (SHARx) }\end{array}$ & $\begin{array}{l}\text { Sligo Regional } \\
\text { Hospital, Sligo, } \\
\text { Ireland }\end{array}$ & & $x$ & & & $x$ & $x$ & \\
\hline SpectrumCalgary & $\begin{array}{l}\text { University of Calgary, } \\
\text { Calgary, Alberta }\end{array}$ & $x$ & $x$ & & $x$ & $x$ & $x$ & $x$ \\
\hline $\begin{array}{l}\text { TARGeT (Toronto Area } \\
\text { Resistance rates and } \\
\text { Guidelines to Treatment) }\end{array}$ & $\begin{array}{l}\text { St Michael's Hospital, } \\
\text { Toronto, Ontario }\end{array}$ & $x$ & $x$ & & & & & \\
\hline
\end{tabular}

The ANTIBIOKOS software, implemented at the Centre de santé et des services sociaux de Rimouski-Neigette, Québec, which includes algorithms also designed to facilitate audit and feedback, demonstrated positive results in its first few months of use; further analysis will be needed to appraise the effect of this software (22). At Sunnybrook Health Sciences Centre in Toronto (Ontario), a real-time integrated database, Stewardship Program Integrating Resource Information Technology (SPIRIT), augments ASP functions and efficiency (23).

Although sophisticated EHR ASP functionality has the most promise for optimizing antimicrobial use, its realization may be remote in time for many Canadian health regions that were only recently mandated to form groups that consider antibiotic use. Furthermore, the time, financial and personnel investment required for such platforms to be successful is substantial. The creation of algorithms and alerts need many months to go live, and ongoing maintenance, updates and evaluation require significant investments in human resources. For example, the NorthShore (NorthShore University HealthSystem, University of Chicago, Illinois, USA) CDS Committee consists of five physicians, nine clinical analytics developers, two EHR trainers, three nurses, and a pharmacist and quality improvement specialist (24). In addition, usability testing is labour intensive but essential for user acceptance of the system, as well as important from a patient safety standpoint to identify any potential risks.

Stewardship-related smartphone applications (apps) are an avenue for reaching prescribers that is likely achievable for many Canadian ASPs. There is no longer any doubt that mobile apps are the desired medium for the consumption of medical information for prescribers at the point of care (25). Central to the rise of the medical app, is the convenience of a multitude of references in a single device that can provide actionable information in seconds.
Many traditional ID references have smartphone customized versions (for example Sanford Guide) and were reviewed in 2013 (26); however, there was little in the way of stewardship-specific or locally relevant content. In the short time since, there have been a number of apps released with a local stewardship focus (Table 1). An Internet search in August 2015 revealed 11 English language apps mainly from the United Kingdom and US with a definite stewardship focus, ranging from relatively 'flat' text clinical guidelines to interactive and algorithmic platforms with alerts, calculators and customized recommendations based on data input. Probably the first of its kind, the Imperial Antibiotic Prescribing Policy, from Imperial College London (London, England), was first released in 2011. The creators have published a description of its development and uptake, including user survey and usage data (27). An important finding outside of nearly universal downloads, was that information was accessed nearly 10 times more often from the app compared with the ASP website.

In Canada, Bugs and Drugs, the most comprehensive Canadian ID guide has created an easily navigable app for both iPhone (Apple, Inc, USA) and Android (Google, USA) devices. The Spectrum App is a stewardship-focused iPhone app that was released in November 2014, as a trainee-led initiative piloted at the University of Calgary (Calgary, Alberta). The app has locally adapted guidelines in a unique algorithmic format, antibiograms, microbiology and pharmacology, including a renal dosing calculator, infection control recommendations, and it has undergone usability testing. It is anticipated that other Canadian apps are in various stages of development.

Canadian stewardship budgets are generally small and heavily focused on human resources rather than technology. In the Canadian ASP context, funding an app is likely an attainable goal. In fact, funds used to design and copy pocketcards are not insignificant (27) and 
could be diverted to app development. A standalone app circumvents the complexities and time delays associated with interfacing with an EHR, enabling corrections, improvements and content growth on a more rapid timescale. Usage data can easily be collected to demonstrate to an ASP that recommendations are actually being accessed. Stewardship content in app format provides some well needed 'sex appeal' compared with the pocket card. Apps can also be used to alert users to local epidemiological trends, such as the start of influenza season, as well as to facilitate communication with the ASP. Provided that an app has sufficient usability and is useful/time saving for the physician, uptake should occur with little marketing because most medical apps are downloaded based on word-of-mouth recommendations (28). As an example, SpectrumCalgary has $>2000$ downloads within Alberta, and $>200$ sessions per day despite no specific marketing campaign (personal data, Elizabeth Parfitt). Outside of lacking EHR integration and data collection, important limitations of apps include passivity - the prescriber can bypass content if not downloaded or used - similar to the fate of the pocketcard. Furthermore, there is currently no base of evidence that antimicrobial stewardship apps influence prescribing, although such studies are undoubtedly underway.

\section{REFERENCES}

1. Silver L. Challenges of antibacterial discovery. Clin Microbiol Rev 2011;24:71-109.

2. World Health Organization. Antimicrobial resistance: Global report on surveillance 2014. <http://apps.who.int/iris/ bitstream/10665/112642/1/9789241564748_eng.pdf?ua=1> (Accessed August 29, 2015)

3. Magill S, Edwards J, Beldavs Z, et al. Prevalence of antimicrobial use in US acute care hospitals, May-September 2011. JAMA 2014;312:1438-46.

4. McGowan J Jr. Antimicrobial resistance in hospital organisms and its relation to antibiotic use. Rev Infect Dis 1983;5:1033-48.

5. Voor In 't Holt AF, Severin J, Lesaffre E, Vos M. A systematic review and meta-analyses show that carbapenem use and medical devices are the leading risk factors for carbapenem-resistant Pseudomonas aeruginosa. Antimicrob Agents Chemother 2014;58:2626-37

6. Accreditation Canada. Required Organizational Practices Handbook 2015. <www.accreditation.ca/sites/default/files/rophandbook-en.pdf> (Accessed August 24, 2015).

7. Dellit T, Owens R, McGowan J, et al. Policy statement on antimicrobial stewardship by the Society for Healthcare Epidemiology of America (SHEA), the Infectious Diseases Society of America (IDSA), and the Pediatric Infectious Diseases Society (PIDS). Infect Control Hosp Epidemiol 2012;33:322-7.

8. Valiquette L, Cossette B, Garant M, Diab H, Pepin J. Impact of a reduction in the use of high-risk antibiotics on the course of an epidemic of Clostridium difficile-associated disease caused by the hypervirulent NAP1/027 strain. Clin Infect Dis 2007;45(Suppl 2):S112-21.

9. Hicks L, Taylor T, Jr., Hunkler R. U.S. outpatient antibiotic prescribing, 2010. N Engl J Med 2013;368:1461-2.

10. Charani E, Edwards R, Sevdalis N, et al. Behavior change strategies to influence antimicrobial prescribing in acute care: A systematic review. Clin Infect Dis 2011;53:651-62.

11. Canadian Institutes of Health Research. More About Knowledge Translation at CIHR. < www.cihr-irsc.gc.ca/e/39033.html> (Accessed August 24, 2015).

12. Parrino T. Controlled trials to improve antibiotic utilization: A systematic review of experience, 1984-2004. Pharmacotherapy 2005;25:289-98.

13. Cabana M, Rand C, Powe N, et al. Why don't physicians follow clinical practice guidelines? A framework for improvement. JAMA 1999;282:1458-65.

14. Kawamoto K, Houlihan C, Balas E, Lobach D. Improving clinical practice using clinical decision support systems: A systematic review of trials to identify features critical to success. BMJ 2005;330:765.

15. Cook P, Rizzo S, Gooch M, et al. Sustained reduction in antimicrobial use and decrease in methicillin-resistant
With many Canadian ASPs in their infancy, it is an opportune time to reflect on available strategies and resources for achieving program goals. As businesses have left sandwichboard marketing by the wayside in favour of social media, our outdated efforts to reach physicians, with supposedly vital information, would appear laughable from an outside perspective. IT can transform ASP processes and data collection, improving accuracy, efficiency and costs. For many Canadian ASPs, customized apps may represent a rapidly feasible way to connect with prescribers, and EHR-integrated software and clinical decision support systems show immense promise despite substantial initiation costs. Although low-fi interventions can be successful, it is time to get with the program(mers) and start investing in IT solutions for stewardship.

DISCLOSURES: Elizabeth Parfitt is one of the creators of SpectrumCalgary, but has no financial gain related to its implementation. Development was funded by the Alberta Sepsis Network. Louis Valiquette has cofounded Lumed Inc, the company that commercializes APSS in Canada. He is also a shareholder and medical advisor to Lumed Inc (www.lumed.ca).
Staphylococcus aureus and Clostridium difficile infections following implementation of an electronic medical record at a tertiary-care teaching hospital. J Antimicrob Chemother 2011;66:205-9.

16. Forrest G, Van Schooneveld T, Kullar R, et al. Use of electronic health records and clinical decision support systems for antimicrobial stewardship. Clin Infect Dis 2014;59(Suppl 3):S122-33.

17. Erlandson R. Universal and Accessible Design for Products, Services, and Processes. Boca Raton, Florida: CFC Press. Taylor \& Francis Group, LLC 2008:133.

18. United States Department of Human \& Health Services. Health Information Technology for Economic and Clinical Health Act, 2009. < www.hhs.gov/ocr/privacy/hipaa/understanding/ coveredentities/hitechact.pdf $>$ (Accessed: August 28, 2015).

19. United States Department of Human \& Health Services Press Release: Doctors and hospitals' use of health IT more than doubles since 2012, Released May 22, 2013. <www.hhs.gov/news/ press/2013pres/05/20130522a.html> (Acessed: August 24, 2015).

20. Kullar R, Goff D, Schulz L, Fox B, Rose W. The "epic" challenge of optimizing antimicrobial stewardship: The role of electronic medical records and technology. Clin Infect Dis 2013;57:1005-13.

21. Nault V, Beaudoin M, Perron J, Valiquette L. Antimicrobial Prescription Surveillance System APSS: A persistent impact after 20 months of use. IDWeek 2013 San Francisco, California. (Abst).

22. Dolce P, Labrecque E, Boivin A, Bernatchez H. Real-time computer-generated alerts to select interventions and optimize an antimicrobial stewardship program. Association of Medical Microbiology and Infectious Disease Canada Annual Conference 2015 Vancouver, BC. (Abst).

23. Elligsen M, Walker S, Simor A, Daneman N. Prospective audit and feedback of antimicrobial stewardship in critical care: Program implementation, experience, and challenges. Can J Hosp Pharm 2012;65:31-6.

24. Wright M, Robicsek A. Clinical decision support systems and infection prevention: to know is not enough. Am J Infect Control 2015;43:554-8.

25. Epocrates. 2013 Mobile Trends Report: Maximizing Multi-screen Engagement Among Clinicians. <www.epocrates.com/sites/default/ files/2013_Epocrates_Mobile_Trends_Report_FINAL.pdf> (Accessed August 28, 2015).

26. Goff D. iPhones, iPads, and medical applications for antimicrobial stewardship. Pharmacotherapy 2012;32:657-61.

27. Charani E, Kyratsis Y, Lawson W, et al. An analysis of the development and implementation of a smartphone application for the delivery of antimicrobial prescribing policy: Lessons learnt. J Antimicrob Chemother 2013;68:960-7.

28. mHealth News. Epocrates study cites advantages to providers and patients in using drug reference apps. <www.mhealthnews.com/ news/epocrates-study-cites-advantages-providers-and-patients-usingdrug-reference-apps?page $=0>($ Accessed August 25, 2015) . 


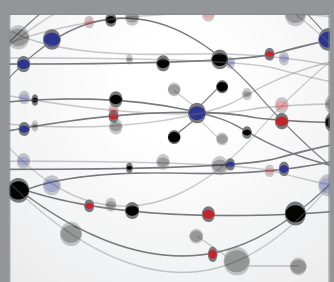

The Scientific World Journal
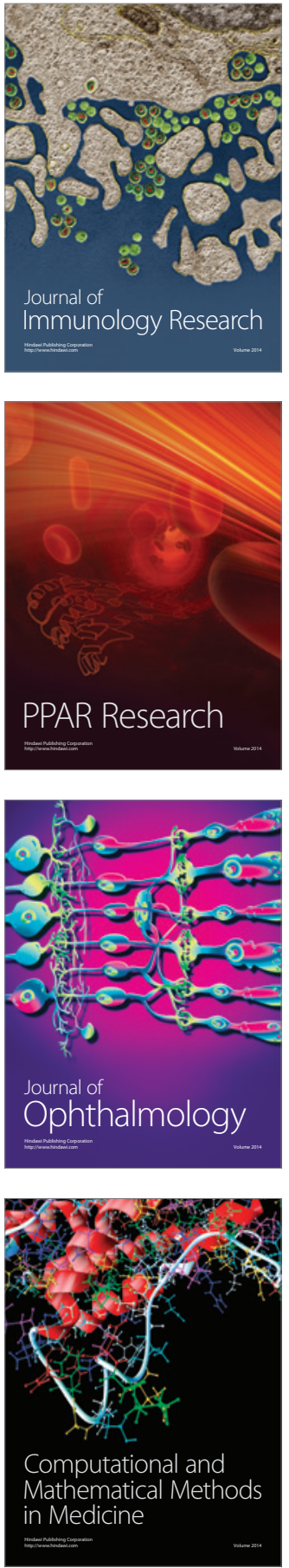

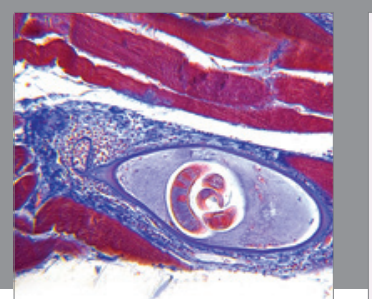

Gastroenterology Research and Practice

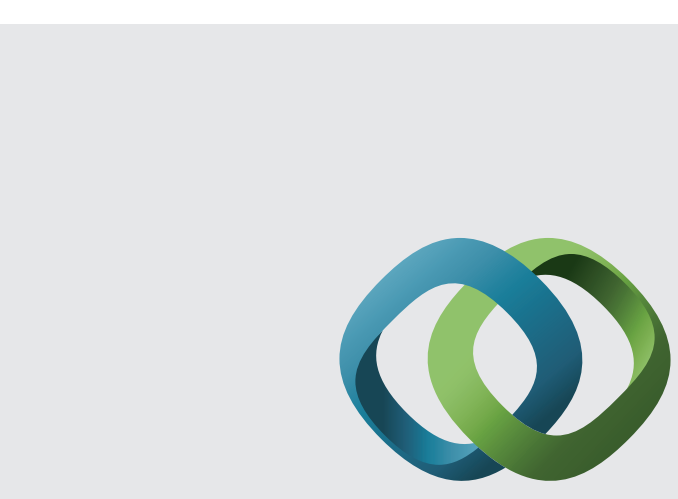

\section{Hindawi}

Submit your manuscripts at

http://www.hindawi.com
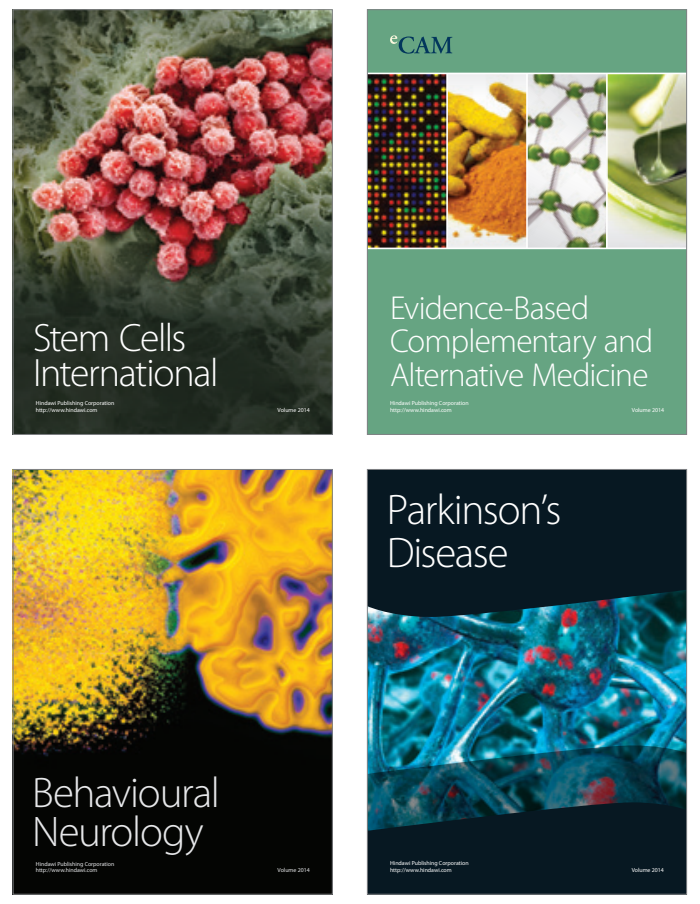
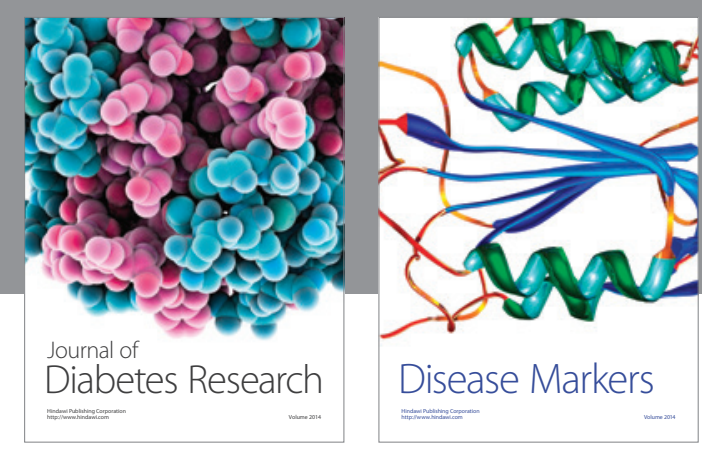

Disease Markers
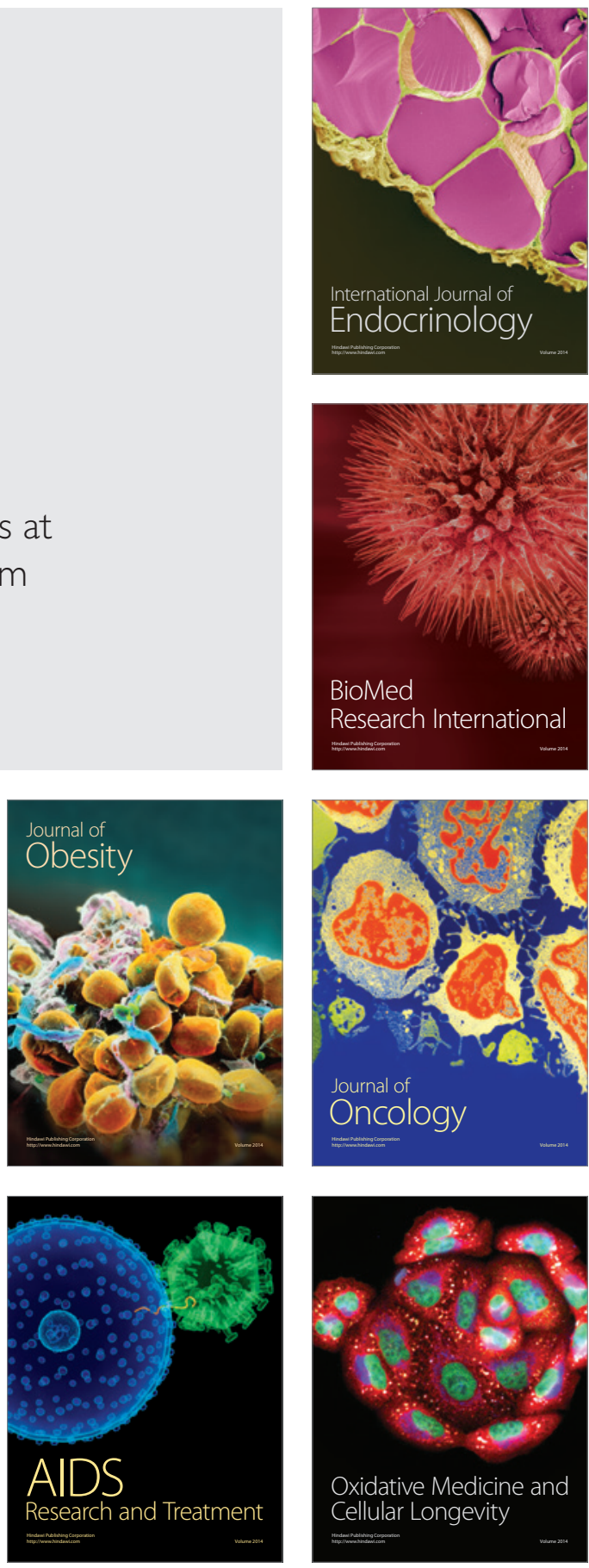